\title{
MÉXICO: DE LA DICTADURA PERFECTA A LA DEMOCRACIA IMPERFECTA
}

\author{
Dr. Cuauhtémoc López Guzmán ${ }^{1}$
}

Resumen. En este documento se utiliza la teoría neo institucional para explicar las claves del funcionamiento atípico del sistema autoritario mexicano el cual represento un reto interpretativo para distintas escuelas de la ciencia política. Para conectar el pasado autoritario con el proceso de consolidación democrática se comparan las críticas al sistema presidencial que formuló Juan Linz y las variables de comparación de Leonardo Molino y Wolfgang Merkel sobre la calidad democrática. Con el uso de estos enfoques sostenemos que para comprender el funcionamiento de la democracia mexicana es necesario entender la herencia institucional autoritaria que ha trasladado desde el pasado reciente la debilidad del Estado de derecho y la preeminencia de las instituciones informales.

Estas dos anomalías institucionales que perviven hoy hacen muy confuso el desempeño democrático de México. Por tal motivo propongo que se use el concepto ${ }^{\cdots}$ Desempeño Democrático... en vez del termino calidad democrática para contar con diagnósticos y evaluaciones más precisas vinculando el orden institucional, la historia y la ideología.

Palabras Clave: Democracia, instituciones, neoinstitucionalismo, autoritarismo, transición

Abstract. This article uses neo institutional theory to explain the keys to the atypical functioning of the Mexican authoritarian system, which represented an interpretive challenge for different schools of political science. To connect the authoritarian past with the process of democratic consolidation, we compare the criticisms of the presidential system formulated by Juan Linz and the comparison variables of Leonardo Molino and Wolfgang Merkel on democratic quality. With the use of these approaches, we maintain that in order to understand the functioning of Mexican democracy, it is necessary to understand the

\footnotetext{
${ }^{1}$ Doctor con mención honorifica en Ciencia Política por la Facultad de Ciencias Políticas de la Universidad Nacional Autónoma de México. Tiene el grado de Maestría en Economía Internacional por la Facultad de Economía de la Universidad Autónoma Baja California (UABC). Miembro en tres periodos consecutivos del Sistema Nacional de Investigadores y líder del Cuerpo Académico de Ciencia Política de la UABC. Es miembro de la International Society for New Institutional Economics agrupación que integra a investigadores que aplican la teoría neo-institucional en sus investigaciones y publicaciones en las áreas de economía y ciencia política.
} 
authoritarian institutional heritage that has transferred the weakness of the rule of law and the preponderance of informal institutions from the past to the present.

Two institutional anomalies that persist today make the democratic performance of Mexico very confusing. For this reason, I propose that the concept of "Democratic Performance" be used instead of the term democratic quality to have more accurate diagnoses and evaluations linking institutional order, history and ideology.

Key words: democracy, institutions, neo-institutionalism, authoritarianism, transition.

\section{Introducción}

En agosto de 1990 se celebró en México un debate y reflexión titulado El siglo XX: la experiencia de la libertad trasmitido por televisa en donde el poeta Mario Vargas Llosa definió al régimen del Partido Revolucionario Institucional como la dictadura perfecta. Más tarde en 2011 este poeta peruano se retractó de tal afirmación, señalando que México había transitado a una democracia imperfecta.

La definición se volvió tan popular que hasta una película mexicana lleva ese nombre, para el común de la gente esta frase envuelve y sintetiza la misteriosa longevidad y funcionalidad de un sistema autoritario y corrupto.

En aquella ocasión (1990) Vargas llosa señalo que el régimen priista no era una típica y vulgar dictadura, y menciono que con modalidades atípicas de funcionamiento daba la apariencia de ser un sistema plural, tolerante y competitivo. Ante esta ambigüedad Enrique Krauze sentencio entonces que México no era una dictadura, sino una dictablanda.

Por su parte Octavio Paz cuestiono ambas posturas, pues dijo caían en la imprecisión y la confusión, él le llamo régimen hegemónico de dominación, concepto tomado seguramente del politólogo italiano Giovanni Sartori de sistema de partido hegemónico.

La confusión en la definición del sistema político mexicano en el pasado se ha heredado hoy a la democracia mexicana, en este trabajo usaremos el herramental teórico de la ciencia política en general y del neo institucionalismo en particular para descifrar esta misteriosa, 
incomprendida y sui generis funcionalidad institucional, tanto bajo un orden autoritario como democrático.

\section{Características del sistema político mexicano en la fase autoritaria.}

En las décadas de los años cincuenta y sesenta del siglo pasado el sistema político mexicano empezó a ser estudiado por los politólogos norteamericanos, el interés y atracción por su estudio no residía en la vecindad, sino en la naturaleza compleja de su funcionamiento, en su bidimensionalidad sistémica y en la fuente originaria del sistema: la revolución mexicana.

Desde entonces han surgido cientos de estudios e interpretaciones del sistema político mexicano, Molinar Horcasitas (1993) en un extenso y denso artículo agrupo a gran parte de los estudiosos del tema, clasificándolos en tres escuelas. De acuerdo a las hipótesis y a la aplicación de un paradigma de investigación Molinar Horcasitas(1993) clasifico a cada investigador en una escuela en particular, así él identificó tres escuelas de interpretación del sistema político mexicano: La pluralista, la autoritarista y la marxista.

La confusión interpretativa del sistema político mexicano no es nueva para la ciencia política, fuera de las aulas universitarias la frase de Mario Vargas Llosa fue esclarecedora, al decir que es una dictadura perfecta, perfecta porque no lo parece y dictadura porque no existía pluralismo político.

Los primeros en confundirse, en imprecisiones conceptuales y ambiguas fueron los politólogos norte americanos identificados por Horcasistas como pertenecientes a la escuela pluralista

Los pluralistas partían de la hipótesis que la Modernización (entiéndase industrialización) generaba la pluralización de la sociedad, y ello llevaba a la democratización. Por aquellos años (1955-1965) México se encontraba en una fase acelerada de su proceso de modernización, bajo el modelo denominado Industrialización por Sustitución de Importaciones (ISI). 
Los pluralistas desde el enfoque institucional aceptaban la óptima y necesaria relación entre las instituciones del capitalismo y la democracia; por ello suponían que México al experimentar un proceso intensivo y acelerado de industrialización, -la modernización social y el pluralismo resultante de dicho proceso- daría como resultado la vigencia de un sistema democrático.

Sin embargo, al aceptar esta relación lineal, irreversible y unidireccional de modernizaciónpluralismo-democracia los pluralistas aceptaban que México todavía no era moderno (estaba en ese proceso) y por lo tanto no democrático. Desde el enfoque institucional el capitalismo y la democracia se auto refuerzan; es decir desde esta perspectiva no pueden existir países modernos sin democracia, o países democráticos no modernos.

En sus conclusiones de investigación doctoral sobre el sistema político mexicano los politólogos y economistas norteamericanos dejan ver esta confusión conceptual, deductiva y disímbola.

Ellos decían que como México no era un país moderno (plenamente capitalista) no era democrático, pero al intentar ubicar a México como una dictadura, decían que no lo era, pues no exista un monarca, o un dictador militar.

Aquí empezaba la confusión, pues México no tenía un régimen democrático como los Estados Unidos, pero tampoco era una dictadura como la Unión Soviética, entonces en que casillero se debía ubicar al régimen priista.

Sus definiciones fueron que México era una semi-democracia, para otros una semidictadura., un sistema pre democrático, un democracia tutelar, o una democracia unipartidista Fue hasta la década de los años 70s del siglo pasado que fue posible ubicar a México en un casillero conceptual. Gracias a Juan Linz, (politólogo español) quien desarrollo la teoría del 
autoritarismo y con ello esta escuela (la autoritarita) desbanco a los pluralistas ante la imposibilidad de definir al sistema político mexicano un par de décadas atrás.

Para avanzar sobre esta escuela habremos primero de citar el concepto de autoritarismo de Juan Linz. '..El eje de su definición es el límite que desde la cúspide dela pirámide del poder se impone al pluralismo político. En este modelo, el poder ejecutivo es la variable independiente y la red de grupos y organizaciones que representan los diversos intereses sociales son la dependiente. La unidad básica del sistema no es el individuo sino el grupo o la corporación. El control de esas organizaciones políticas y sociales es vertical y el centro político trata de evitar la existencia de relaciones horizontales. Los liderazgos intermedios deben su posición menos al consentimiento de las bases y más a la aprobación y apoyo del poder central.

La función central de esos líderes intermedios no es tanto expresar las demandas de su membresía, sino moldearlas y controlarlas según los intereses y proyectos de la cúpula de la pirámide del poder. En estas circunstancias el ejercicio del poder es básicamente patrimonial y clientelistico. ${ }^{2}$

\footnotetext{
${ }^{2}$ Meyer Lorenzo, “El límite Neoliberal”' Revista Nexos No. 163 Pág. 25. México.1991.
} 
El diagrama 1: ilustración del concepto de autoritarismo de Juan Linz.

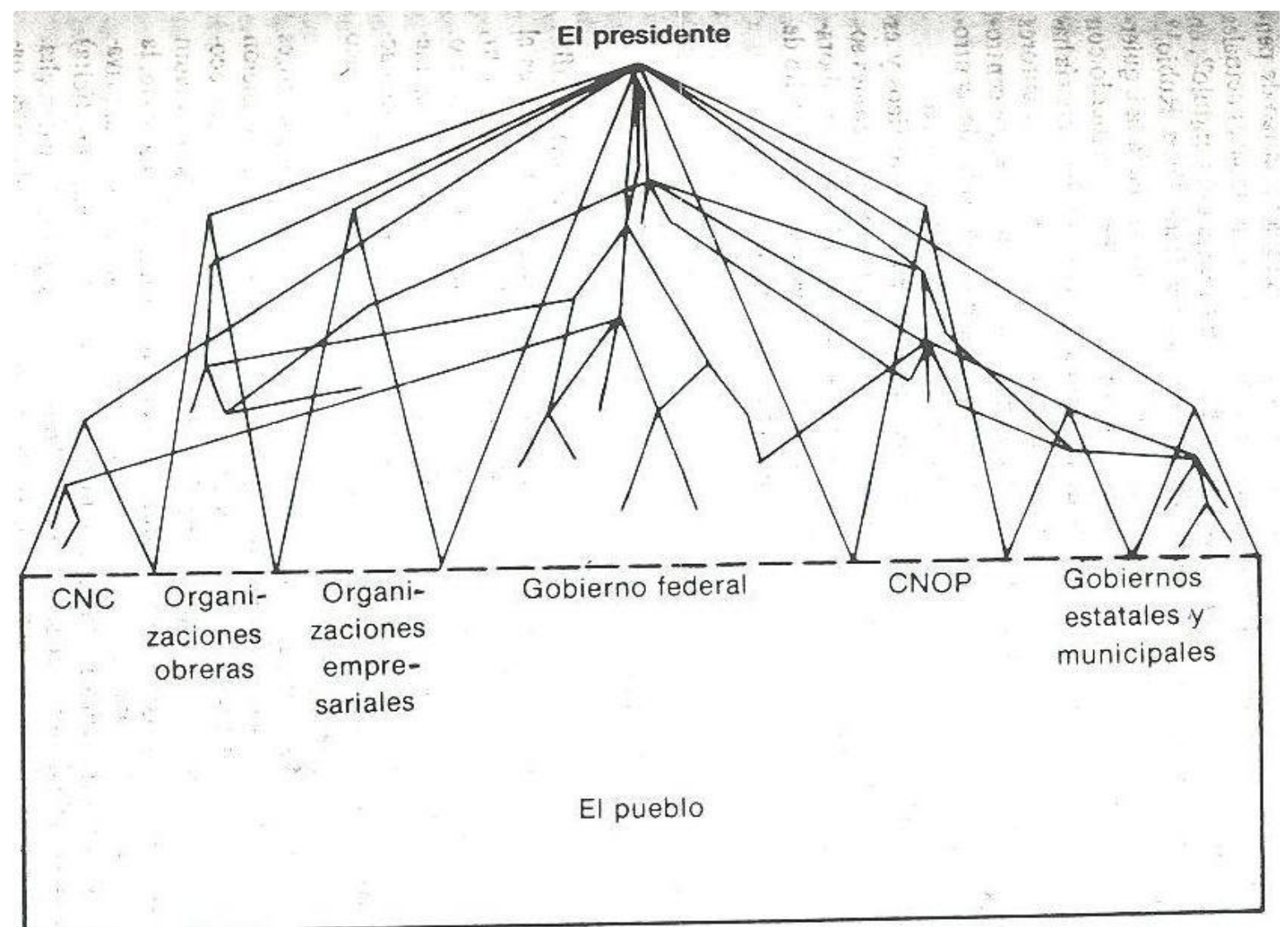

Diagrama 1. Fuente: La lucha por la hegemonía en México. Miguel Basáñez. Siglo XXI. Pág. 44.

Los autoritaristas coincidían con los pluralistas al considerar que la modernización generaba la pluralización de la sociedad, pero se oponían a la idea de que este proceso conducía a la democratización; por el contrario, sostenían que para garantizar el proceso de acumulación originaria de capital (industrialización) se requería un orden militar dictatorial que limitara las luchas clasistas, obreras -sindicales desestabilizadoras. Asegurando así la propiedad privada de los medios de producción y el retorno de las inversiones a la clase empresarial autóctona y extranjera. 
Una vez consolidada la interpretación autoritaria del sistema político mexicano surge un debate académico con los marxistas principalmente en torno al grado o intensidad autoritario del régimen priista. Si en los setentas la instauración de dictaduras militares en América del Sur les otorgo a la escuela autoritaria la validez empírica de la premisa arriba explicada y con ello el prestigio intelectual de sus miembros; lo complicado fue explicar porque el gobierno mexicano (autoritario) recibía, protegía y promovía a los exiliados de las dictaduras militares de Sudamérica: Argentinos, chilenos, uruguayos, paraguayos.

Muy por el contrario el gobierno mexicano condenaba a los gobiernos militares, en vez de apoyarlos o impedir la llegada de exiliados marxistas y de miembros de partidos comunistas Sudamericanos.

Este extraño comportamiento del régimen autoritario mexicano ocasiono un intenso debate y reflexión, por lo que los miembros de la escuela autoritaria sacudidos ideológicamente por esta realidad terminaron por aceptar que el sistema autoritario mexicano era un caso excepcional, sui generis, atípico.

Sin embargo, sin estar de acuerdo sobre una nueva definición y ubicación conceptual terminaron por aceptar que el régimen posrevolucionario habría abortado un sistema autoritario limitado, o autoritarismo light sin parangón en el mundo.

En cambio, los marxistas centraban su análisis del sistema político mexicano bajo la premisa que la clase gobernante mexicana se hallaba subordinada a la burguesía y el Estado mexicano era un instrumento de dominación de la clase burguesa. Para los marxistas lo autoritario o democrático del régimen era irrelevante. El Estado mexicano era un Estado burgués y estaba sujeto a las leyes del cambio definidas por la lucha de clases y el materialismo histórico.

Los pluralistas (norteamericanos la mayoría) se impresionaron del proceso de modernización de México en la década de los sesenta -al que bautizaron como el milagro mexicano- 
señalando con optimismo que México llegaría al desarrollo y la democracia. Sin tener capacidad de definir al régimen priista se conformaron con decir que México era un país pre moderno y pre democrático.

Para los autoritaristas la confusión derivo del carácter benévolo del régimen frente a oros regímenes totalitarios.

Para los marxistas esta confusión conceptual estuvo dada por la relativa autonomía de la clase gobernante pues varios miembros de esta escuela aceptaron que no era la clase burguesa quien detentaba el poder, ni tampoco el proletariado. La idea de que ninguna de las dos clases gano la revolución, ni tomo el poder les impuso limites, contradicciones y confusiones.

Usando el concepto de bonapartismo los marxistas pudieron -en parte- salvar esta contradicción señalando que -una clase media,- gestora y mediadora del conflicto clasista tomo el poder. Ante el empate catastrófico de la lucha de clases en la revolución fue necesaria una alianza clasista para imponer el capitalismo monopolista de Estado, que en última instancia deberá consolidar el dominio de la burguesía.

Aquellos marxistas (los menos) que decían que la revolución la gano el proletariado, tenían que dar cuenta de por qué México no instauro el socialismo; quienes sostenían que gano la burguesía, tenían que dar cuenta de porque México no instauro un régimen democrático con una economía plenamente capitalista.

Después de una revisión crítica a los postulados marxistas sobre la revolución mexicana y el tipo de sistema político he tenido que construir un concepto propio que le dé sentido y coherencia a la contradicción marxista sobre el régimen posrevolucionario.

Este es mi concepto síntesis de tal contradicción: 
..”El régimen posrevolucionario y el sistema político mexicano son el resultado de una revolución burguesa inacabada, la cual fortaleció los rasgos autoritarios y corporativistas que sustituyeron eficazmente la ausencia de democracia. Por otra parte, le neutralización y manipulación de la revolución proletaria gesto el carácter populista y mediador del Estado mexicano."

Una vez enfatizado que desde la academia, las distintas vertientes interpretativas fracasaron en su intento de desentrañar las rarezas funcionales del régimen autoritario mexicano. Hoy ante la aceptación de que el régimen mexicano era un sistema de autoritarismo limitado nos enfocamos en precisar las características de este sistema sui generis. Construimos cuadros para agrupar las características de un sistema autoritario típico versus el formato mexicano de autoritarismo limitado. Esperando que tanto Krauze como Vargas Llosa lo consideren como una guía para corregir las exóticas definiciones que han acuñado del régimen priista.

Cuadro 1. Características del autoritarismo mexicano.

\begin{tabular}{|l|l|l|}
\hline VARIABLES & AUTORITARISMO TÍPICO & $\begin{array}{l}\text { AUTORITARISMO } \\
\text { LIMITADO (México) }\end{array}$ \\
\hline Quien gobierna & $\begin{array}{l}\text { Dictaduras militares u oligarquías } \\
\text { reaccionarias }\end{array}$ & Elite política civil y populista \\
\hline Nivel de oposición partidista & Inexistente o mínimo & Limitado y/o articulado al Estado \\
\hline $\begin{array}{l}\text { Tipo de disenso y opinión publica } \\
\text { independiente }\end{array}$ & Clandestina y reprimida & Abierta pero limitada \\
\hline $\begin{array}{l}\text { Grado de rotación política de las } \\
\text { elites }\end{array}$ & Lento y escalonar & Circular y cruzado \\
\hline $\begin{array}{l}\text { Tipo de acción sobre movimientos } \\
\text { disidentes }\end{array}$ & $\begin{array}{l}\text { Represión sistémica de } \\
\text { exterminio }\end{array}$ & Represión focal de neutralización \\
\hline
\end{tabular}

Fuente: Elaboración del autor. 


\section{Cuadro 2. Continuación.}

\begin{tabular}{|l|l|l|}
\hline VARIABLES & AUTORITARISMO TÍPICO & $\begin{array}{l}\text { AUTORITARISMO } \\
\text { LIMITADO (México) }\end{array}$ \\
\hline Articulación social con las masas & Fascista- corporativa & Populista -corporativa \\
\hline Legitimación de origen & Militar mesiánico & Popular- revolucionaria \\
\hline Nivel de competencia partidista & No competitivo & Semi competitivo \\
\hline Ideología dominante & Elitista y fascista & Multicorrientes y ecléctica \\
\hline Tipo de partido & Dogmático de cuadros & Pragmático, de masas \\
\hline
\end{tabular}

Fuente: Elaboración del autor.

\section{Cuadro 3. Continuación.}

\begin{tabular}{|l|l|l|}
\hline VARIABLES & AUTORITARISMO TÍPICO & $\begin{array}{l}\text { AUTORITARISMO } \\
\text { LIMITADO (México) }\end{array}$ \\
\hline $\begin{array}{l}\text { Procesamiento de conflictos } \\
\text { políticos }\end{array}$ & Alineación y subordinación & Pactos y alianzas clasistas \\
\hline $\begin{array}{l}\text { Méritos y requisitos de ascenso al } \\
\text { poder }\end{array}$ & Carrera militar y/o tecnocrática & $\begin{array}{l}\text { Habilidades de negociación y } \\
\text { pertenencia a un grupo político }\end{array}$ \\
\hline Medio de ascenso al poder & Golpe de Estado & Manipulación electoral \\
\hline Ejecución de políticas & Burocrático-autoritarias & Populistas \\
\hline
\end{tabular}

Fuente: Elaboración del autor

\section{Revelando el misterio analítico del sistema político mexicano: instituciones formales versus instituciones informales.}

Si en el pasado los politólogos, académicos y científicos sociales se enfrentaron a confusiones interpretativas sobre el sistema político mexicano en parte se debió al uso de paradigmas sesgados por la mono disciplinariedad.

Además de la uni disciplinariedad existía la rivalidad interpretativa entre teorías y paradigmas dentro de una disciplina en particular. Esta situación limito y obligo a los investigadores a forzar el embone de la realidad a su paradigma analítico.

En la interpretación del sistema político mexicano participaron desde la década de los 50s del siglo pasado extranjeros y mexicanos surgidos de las carreras de ciencia política, 
economía, y sociología; algunos en formación doctoral o como investigadores adscriptos a centros de investigación o universidades de prestigio internacional.

El paisaje interpretativo floreció y con ello el caudal de confusiones y contradicciones que enemistaron a los portadores de una verdad interpretativa acuñada en la academia.

La competencia interpretativa se dio a través de grupos de investigadores identificados con una disciplina dentro de una escuela, así se fortaleció la unidisciplinariedad como proceso natural de especialización.

Surgió así una en rivalidad con otros investigadores, ya sea por el apego a una teoría, o por su empleo de métodos y paradigmas validados por unos y rechazados por otros; en particular por el tipo de investigación, una de tipo cualitativo, otras de tipo cuantitativa.

Ahora para rebasar estas limitaciones interpretativas del pasado de nuestro sistema político emplearemos la teoría neo institucional y el paradigma derivado de esta teoría denominado análisis político de costos de transacción política.

En necesario, en primer lugar definir el concepto de instituciones y su diferenciación entre formales e informales. Empelaremos los conceptos de Douglass North, dejando en claro que hay cientos de conceptos sobre instituciones, pero en apego del suscrito a la teoría neo institucional acudo a este autor, premio nobel de economía en 1993.

\section{Concepto de instituciones:}

“Las instituciones son las reglas del juego en una sociedad, más formalmente, son la limitaciones ideadas por el hombre que dan forma a la interacción humana. Por consiguiente, estructuran incentivos en el intercambio humano, sea político, social o económico. El cambio 
institucional conforma el modo en que las sociedades evolucionan a lo largo del tiempo, por lo cual es la clave para entender el cambio histórico. ${ }^{3}$

\section{Concepto de instituciones formales:}

Por instituciones formales debemos entender las constituciones, leyes, normas y reglamentos que tienen un carácter público obligatorio (creadas por el hombre).

\section{Concepto de instituciones informales}

Por otra parte las instituciones informales (evolutivas) como la cultura, costumbres, valores, ritos y convencionalismos sociales son el resultado de la necesidad del hombre de estructurar las relaciones humanas para guiar la conducta y limitar la incertidumbre.

*La función principal de las instituciones en la sociedad es reducir la incertidumbre estableciendo una estructura estable (pero no necesariamente eficiente) de la interacción humana. Pero la estabilidad de las instituciones de ningún modo contradice el hecho de que estén en cambio permanente. ${ }^{4}$

Los individuos se guían en toda sociedad por instituciones formales e informales, la conducta y las decisiones siempre están limitadas por ambas dimensiones. La importancia de conciliar ambas dimensiones radica en la necesidad de ordenar la vida social y personal bajo parámetros de eficiencia, certeza o valores.

Así los individuos pueden conocer o evaluar sus actos y acciones en relación a las posibilidades o restricciones que impone un orden institucional cualquiera sea este.

Aquí aparecen cuatro componentes de la conducta individual ante un orden institucional: la racionalidad, la ideología, el oportunismo y los costos de transacción.

\footnotetext{
${ }^{3}$ North Douglass C. Instituciones, cambio institucional y desempeño económico. Fondo de Cultura Economica. México. 1993. p. 13

${ }^{4}$ Op Cit. P. 16
} 
La racionalidad se refiere a que los individuos siempre buscaran las mayores ganancias en sus elecciones, tratando de minimizar pérdidas en cualquier ámbito de la vida; la ideología es una eficaz sustituta de la información incompleta que ayuda a los individuos a guiarse por modelos mentales subjetivos.

En cambio el oportunismo se refiere que ante escases de recursos u oportunidades los individuos siempre tomaran una estrategia de ganar todas las partidas en las que compiten en la vida; aun sin respetar las normas o los valores de una sociedad u organización.

Por costos de transacción entendemos como la restricción o costo que toda institución impone a los individuos en sus intercambios voluntarios, se considera que todo orden institucional debe de existir para reducir los costos de transacción y con ello garantizar la eficiencia institucional.

Una vez recordado estos conceptos clave del neo institucionalismo es preciso puntualizar que esta teoría al combinar economía, leyes, sociología y ciencia política puede sernos útil en la interpretación del sistema político mexicano ya que tiene un marco de referencia multi disciplinario, del que carecieron los pluralistas, autoritaritas y marxistas.

La confusión interpretativa del sistema político mexicano se dio porque los politólogos e investigadores no se percataron que las instituciones formales eran sustituidas a discreción de los intereses de la elite política, o más precisamente por los intereses del ejecutivo federal, incluyendo hacia abajo gobernadores y alcaldes locales.

Las reglas no escritas ligadas a las transacciones políticas determinaron las estrategias de acceso, permanencia y trayectoria política de los individuos dentro de un modelo de partido hegemónico. Paradójicamente, va a ser en el discurso donde se presumió del apego a las instituciones, cuando en realidad estas fueron relegadas por la no funcionalidad instrumental de un sistema diseñado constitucionalmente como democrático pero con una sociedad no plural, ni independiente, ni participativa. 
Es nuestro país después de años de inestabilidad, violencia y dictaduras, sobre todo ante la dificultad para lograr la paz social después de la revolución -Plutarco Elías Calles --en un pasaje histórico muy conocido en México, convocó a las distintas fracciones revolucionarias a dejar las armas en la lucha por el poder y pasar a la obediencia y respeto a las instituciones. Pero justo cuando se intentó estructurar una dinámica institucional de competencia política fue cuando se desvío y empleo el orden informal alternativo para resolver la disputa por el poder.

La dinámica institucional siguió un patrón de sustitución de un orden formal no eficaz para la gobernabilidad; por ello las instituciones informales fueron eficaces para el logro del reparto no violento del poder político, garantizando con ello la gobernabilidad y la estabilidad del sistema. Así pudo funcionar sin crisis ni tensiones graves un orden autoritario que se sustentaba en una constitución democrática de ornato.

La lucha por el poder siempre ha sido un campo de batalla en donde el uso de las reglas informales y el desprecio o evasión de lo legal han sido narrados, documentados y avergüenza la vida cívica nacional. La interrogante es, regresando a la paradoja histórica del cambio institucional en México, ¿porque la obsesión por el aparente apego, aplicación y veneración a las instituciones formales, cuando desde el mismo poder se menoscaba su uso y respeto?

Los arreglos informales de acceso al poder vinculado a un partido hegemónico y un sistema presidencialista autoritario permitieron que la competencia política durante buen tiempo se reciclara entre diversos grupos afiliados al mismo partido (PNR, PRM PRI).

Desde la perspectiva neo institucional no solamente debemos esclarecer la dificultad analítica del sistema político mexicano, sino precisar su desempeño institucional, es decir que condicionamientos colectivos de acción y conducta propicio y como se procesaron las transacciones políticas en un régimen autoritario pero con una ideología revolucionaria. 
Primero: Desde el enfoque neo-institucional en México la notable y ampliamente reconocida dificultad analítica que presenta su sistema político parece tener su origen en la especial relación que existe entre las instituciones formales y las informales, entre las normas escritas y aquéllas no escritas y, que sin embargo en su conjunto, determinan día con día las conductas válidas posibles de todos los actores del sistema, a tal grado que pareciera que las normas e instituciones formales funcionan principalmente para asegurar el funcionamiento en la realidad de las normas e instituciones informales. ${ }^{5}$

Con esta cita dejamos en claro la hipótesis neo institucional; así cumplimos con identificar el origen del funcionamiento ambivalente del sistema político mexicano. Desafortunadamente hay quienes sostienen que esta dinámica perversa continúa hoy bajo un sistema democrático.

Esta ambivalencia le mereció el calificativo al régimen priista de dictadura perfecta; hoy quizás le merezca el calificativo de democracia imperfecta, en ambas situaciones las instituciones formales son sustituidas por las reglas no escritas (instituciones informales). Con ello se distorsionan la conducta de los individuos y vuelven muy confuso y costoso los intercambios y transacciones políticas.

Segundo: A nivel de comportamiento colectivo un sistema institucional distorsionado tuvo efectos perversos en los valores de no participación, de desacato a la ley, así como la falta de respeto a la autoridad, la corrupción e influyentismo --en el ámbito de la política--; lo mismo que la búsqueda de la riqueza por vías no competitivas y la baja propensión a invertir e innovar; así como el fomento de conductas oportunistas fuera de las normas y el mercado-en el ámbito de la economía-- fueron y siguen siendo la estrategia de acción colectiva y de

\footnotetext{
${ }^{5}$ Blum Valenzuela Roberto, De la política mexicana y sus medios: deterioro institucional o nuevo pacto político. Miguel Ángel Porrua. 1996. México.
} 
decisiones individuales que afectan la coordinación, certidumbre e intercambio en la sociedad mexicana.

Estos valores, costumbres, tradiciones y reglas no escritas (instituciones informales) que se consideran formas deficientes socialmente en la actual sociedad mexicana no provienen de una extraña mutación genética producto del mestizaje, sino que son el resultado de una ambivalencia institucional perversa.

Es decir la colectividad imita el comportamiento y valores de su clase gobernante, esto impide por supuesto el fortalecimiento del Estado de derecho, pues muchas veces las leyes son usadas a discreción por los gobernantes y gobernados, alterando las señales de certidumbre, imparcialidad y confianza en las instituciones.

Tercero: La Ideología y los costos de transacción en el régimen autoritario mexicano nos ayudan a explicar con mayor precisión el desempeño institucional que caracterizo a un régimen de origen revolucionario pero que se entrampo en una dinámica transaccional ineficiente.

La ideología según North tiene una doble función, una es interpretar la realidad aceptando el mundo como es, y por otra parte, cuestionando la realidad intentando cambiar el mundo.

En México la ideología revolucionaria construyó instituciones desviadas de una matriz eficiente y equitativa por que el gobernante ( $\sin$ competencia ni pluralismo) concentro en un individuo (presidente de la república) la función de equilibrio entre los poderes de jure y de facto.

La concentración en un individuo de la función distributiva de la riqueza y del poder en el sistema implico altos costos de información, conciliación, transacción y monitoreo para todos los agentes involucrados en cualquier tipo de cambio institucional. 
Al carecer de información perfecta y elevados costos de conciliación el gobernante sometía, solucionaba o salvaba cualquier conflicto amparado en la ideología que además de ser progresista (por ser revolucionaria) ofrecía soluciones óptimas, justas o equitativas sólo por encarnar en la figura del presidente al gran benefactor social. Al ser el gobernante benevolente por su ideología revolucionaria se estaban creando (supuestamente) instituciones que garantizaran el progreso, la justicia y la paz social en México.

Sin embargo, la ideología sirvió para ocultar o maquillar la inequidad distributiva, el bajo nivel competitivo de todos los sectores económicos y la debilidad del Estado de derecho.

La ideología de la revolución mexicana fue también una eficaz cortina de humo que permitió ocultar, bajo su manto de postulados, la ineficiencia de las instituciones y las políticas. Esta peculiar mixtura de ideas, principios y programas funciono mientras la democracia estuvo lejana por que los grupos en el poder recibían beneficios. ${ }^{6}$

Una forma de mantener instituciones ineficientes es reforzando la idea de la estabilidad, para que esto ocurra y los individuos y las organizaciones lo acepten es necesario el uso de medios coercitivos (la ley) y persuasivos (la ideología).

Esta última sobre todo es muy eficaz en contextos donde el marco institucional no provee de certidumbre y garantías sociales, y donde el mercado político funciona de forma monopólica u oligopólica, produciendo mayores costos asociados a obtención de información, asimetrías de poder y racionalidad limitada.

La ideología es pues el insumo social que reduce la incertidumbre, justifica instituciones no eficientes y provee a los actores políticos de información depurada de la complejidad social; que dada su limitación cognitiva introduce altos costos de transacción.

\footnotetext{
6 Ayala Espino José, Instituciones para mejorar el desarrollo: un nuevo pacto social para el crecimiento y el bienestar. FCE. México. 2003. p. 42-43.
} 
Allí donde existen altos costos de transacción (en el mercado político) el cambio institucional es menos probable o al menos más lento, esta afirmación contradice un supuesto central de la teoría neo institucional. La premisa dice que el cambio histórico ocurre cuando el orden institucional no es eficiente, los individuos al incurrir en altos costos de transacción se percataran de la necesaria modificación de esas instituciones.

Si aceptamos que en el marco de un sistema de partido hegemónico, corporativista y con un presidencialismo autoritario se diseñaron instituciones ineficientes e inequitativas, como explicar la incapacidad de corrección de un orden institucional defectuoso si el Presidente de la Republica no enfrentaba límites y resistencias a su vocación social reformista.

Para ejemplificar estas premisas, permítaseme comparar la dinámica del cambio institucional durante el régimen pos revolucionario (1920-2000) y el actual sistema plural y de gobiernos divididos (2001-2016).

En el sistema de partido hegemónico y presidencialismo autoritario se crearon instituciones ineficientes e inequitativas, ¿Por qué entonces durante 70 años o más, bajo una conducción central del poder, donde toda la clase gobernante estaba sometida a la voluntad autoritaria del ejecutivo el cambio institucional hacia la eficiencia y la equidad no se concretó?

Si los costos de transacción políticos eran nulos, en términos de intercambio, pues la voluntad del presidente era acatada por senadores, diputados, gobernadores y legisladores locales, incluyendo al poder judicial. En otras palabras, porque bajo un sistema autoritario las reformas institucionales (con reducidos costos de transacción) no se materializaron en una sociedad más prospera y avanzada.

Hoy, en cambio bajo un sistema de partidos de pluralismo moderado, con gobiernos divididos y fortalecimiento del federalismo, las reformas institucionales enfrentan altos costos de transacción política. Lo que implica que construir una sociedad más moderna y justa se complica, y el instrumento que encarece esta meta es precisamente la democracia. 
A pesar de que bajo un régimen autoritario existan bajos costos de transacción política, el cambio institucional no se orientó a la eficiencia o la equidad, pues los modelos de decisión subjetiva, (ideología revolucionaria) opacaban las distorsiones.

Ahora en cambio, bajo un régimen democrático (la ideología) resalta las distorsiones institucionales. Pero paradójicamente, los actores políticos se hallan entrapados en limitantes cognitivas, de información incompleta, y empleando modelos subjetivos opuestos; todo ello, encarece la toma de decisiones técnicas y racionales que permiten alcanzar el desarrollo y el bienestar para una nación.

*Douglass North por ello ha llamado la atención sobre la necesidad de construir una teoría de la ideología para explicar el proceso de formación de preferencias y como un elemento clave para especificar las limitaciones en la racionalidad de las decisiones de los actores. ${ }^{7}$

Entonces sí en el pasado (bajo un régimen autoritario) se mantuvieron instituciones ineficientes e inequitativas, porqué hoy (bajo un régimen democrático) persisten estas condiciones que frenan el desarrollo y la democracia.

Para explicar el desempeño institucional de la democracia mexicana debemos ponderar nuevas conceptualizaciones sobre la democracia y sumar estas perspectivas al enfoque neo institucional. El siguiente apartado integra estas dimensiones analíticas.

\section{México hoy: democracia imperfecta o defectuosa.}

En este apartado es necesario precisar el desempeño democrático del sistema político mexicano, al usar el término “Desempeño“ queremos hacer notar las variantes institucionales que imponen un determinado ritmo de cambio-continuidad, estabilidad - tensión y duración -agotamiento.

\footnotetext{
${ }^{7}$ Powell Walter W. y Paul J. Dimaggio (compiladores) El nuevo institucionalismo en el análisis organizacional. FCE. 2001. México. P. 17.
} 
Por ello, siendo el sistema político mexicano un orden institucional que funciono con instituciones ineficientes; la incógnita es porque perduro; además fue ejemplo de estabilidad y legitimidad al combinar eficazmente el uso alternativo del orden institucional formal e informal, siempre bajo la lógica discrecional de la clase gobernante.

La clave explicativa para trazar el tránsito de una dictadura perfecta a una democracia imperfecta o defectuosa es abordar esta transición en dos ejes o planos: 1). El mal funcionamiento de los sistemas presidenciales bajo las premisas de Juan Linz, y las definiciones de Leonardo Morlino de democracias imperfectas y de Wolfgang Merkel de democracias defectuosas.

Y 2). La herencia autoritaria del régimen (dependencia de la senda) así como el tipo de cambio institucional que configuro el actual desempeño democrático en México, esto significa identificar como murió un régimen y nació otro. En este eje es necesario instrumentalizar el concepto innovación institucional porque representa la clave para explicar la longevidad del régimen autoritario mexicano.

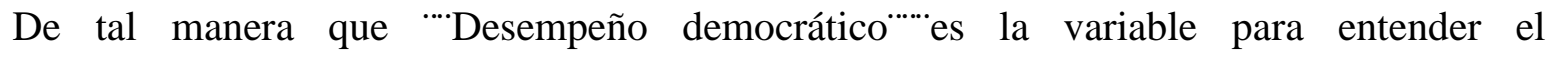
funcionamiento de la democracia mexicana sin la agregación de adjetivos calificativos. Es decir si el régimen pos revolucionario no pudo ser definido por ninguna de las escuelas ya citadas, entonces es muy probable que nuestra democracia no encaje ni en la conceptualización de Linz, de Merkel o Morlino.

Y no porque estos autores no dispongan de refinadas y elegantes hipótesis, sino porque la especificidad transicional de México embono un orden institucional disfuncional entre forma y funciones; lo que paradójicamente incentiva la innovación institucional y caracteriza a los gobiernos actuales. 
Sin embargo los gobernantes no pueden resolver (casi nunca) la exigencia de eficiencia institucional. Es decir cambiar las formas institucionales es relativamente fácil, pero conseguir un funcionamiento eficiente institucionalmente es mucho más complicado.

En respuesta a esta confusión algunos han argumentado que se debe dar preferencia a las variables de función sobre las variables de forma. Estoy totalmente de acuerdo en que las formas particulares de las instituciones no garantizan resultados particulares, como se observa en numerosos fracasos del trasplante institucional. Para decirlo de otra manera, quizá las formas institucionales no importen mucho, puesto que diferentes formas institucionales pueden desempeñar la misma función ${ }^{8}$

\section{Numero uno:}

Para entrar en materia empezamos por identificar la premisa de Juan Linz sobre su crítica a los sistemas presidenciales.

La hipótesis central de Linz es que:

En naciones con profundas divisiones políticas y numerosos partidos políticos, el cargo presidencial introduce un elemento indeseable de competencia donde el ganador se lo lleva todo, en sociedades que en vez de esto necesitan mecanismos de conciliación.

Y sus premisas son:

1. Los regímenes parlamentarios aseguran estabilidad democrática.

2. El sistema presidencial conserva el candado del cargo fijo, lo que puede llevar a crisis de gobernabilidad.

3. El presidente y el legislador poseen legitimidad democrática, en situaciones hostiles y polarizadas quien tiene derecho a hablar de parte del pueblo.

\footnotetext{
${ }^{8}$ Ha-Joon Chang, La relación entre las instituciones y el desarrollo económico: problemas teóricos clave. Revista de Economía Institucional, vol. 8. No. 14, primer semestre de 2006.
} 
4. El desarrollo de partidos políticos modernos en países social e ideológicamente polarizados exacerba los conflictos entre el legislativo y ejecutivo.

5. Las constituciones presidenciales integran principios y supuestos contradictorios (de ejecutivo fuerte y estable vs personalización del poder).

6. El parlamentarismo imprime flexibilidad al proceso político y el presidencialismo lo vuelve rígido.

7. El presidencialismo es problemático porque opera según la norma de que el ganador se lo lleva todo.

8. El juego de suma cero en los regímenes presidenciales aumenta el interés en las elecciones, provocando tensión y conflictos.

9. El cargo del presidente es por naturaleza bidimensional, por un lado el presidente es jefe de Estado y el representante de toda la nación, por otro lado representa una opción claramente partidista.

10. La inestabilidad superficial que acompaña al parlamentarismo (crisis de gabinete) evita crisis que el presidencialismo no puede desahogar en situaciones de impopularidad, corrupción y rechazo del presidente.

11. El tiempo fijo y limitado del cargo del presidente influye en un estilo político afanosamente ambicioso.

12. En caso de muerte o incapacidad del presidente, en algunos casos el sucesor puede ser elegido y representar una opción política diferente a la del presidente, es una paradoja del sistema, que aunque favorece la personalización del poder, en caso de una sucesión repentina puede llevar al poder a alguien a quien el proceso electoral común nunca hubiera hecho jefe de Estado. 
13. En los sistemas de elección por el principio de mayoría relativa él candidato triunfador recibe el cargo con una baja representatividad; ello afecta las posibilidades de introducir o promover cambios de gran alcance en la economía o la política., produciéndose una pérdida de legitimidad del presidente.

En cambio para Leonardo Morlino las democracias imperfectas se caracterizan por no cumplir con los factores que se consideran necesarios para tener una democracia de calidad, estos son:

Estado de derecho

Responsabilidad electoral

Responsabilidad interinstitucional

Reciprocidad

Libertad.

Igualdad.

Para Wolfgang Merkel las democracias defectuosas son definidas en cuatro tipos.

Democracia exclusiva.

Democracia tutelada

Democracia delegativa

Democracia iliberal $^{9}$

En el caso de Juan Linz, la premisa del mal funcionamiento del sistema presidencial bajo mayorías divididas se cumplió en nuestro país, tanto por los factores socioeconómicos, de polarización y desigualdad social; así como por la neutralización del sistema de balances y contra pesos al subordinar a los poderes constitucionales previstos para evitar la concentración del poder en la fase autoritaria, es decir se canceló la división de poderes horizontal y vertical.

\footnotetext{
${ }^{9}$ Le dejo al lector la revisión de los documentos centrales u originales de estos autores. Recomendado a Linz

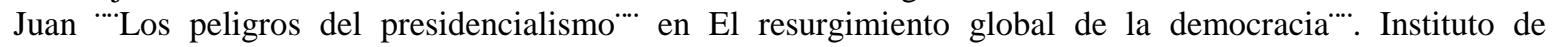
Investigaciones Sociales. UNAM.1996. y Morlino Leonardo, “.'Explicar la calidad democrática: ¿Qué tan relevantes son las tradiciones autoritarias? Revista de Ciencia Política/volumen 27/No. 2/2007. Y Merkel Wolfgang ' 'Democracias iliberales o defectuosas. Universidad. www.idehpucp.pucp.pe
} 
Las premisas del pobre desempeño democrático de los sistemas presidenciales en América latina se agravan con el multipartidismo y una cultura mesiánica -populista heredada de las luchas emancipadoras y revolucionarias que se fundió en la figura del presidente.

Con este panorama Linz sostuvo que solo el sistema parlamentario es capaz de asegurar la estabilidad democrática, (ver cuadro 4).

Cuadro 4. Éxito y fracaso de la democracia de acuerdo al tipo de sistema político.

\begin{tabular}{|l|l|l|l|l|}
\hline & $\begin{array}{l}\text { Democracias } \\
\text { consolidadas } \\
\text { OECD }\end{array}$ & $\begin{array}{l}\text { Democracias } \\
\text { consolidadas } \\
\text { BTI }\end{array}$ & $\begin{array}{l}\text { Democracias } \\
\text { defectuosas } \\
\text { BTI }\end{array}$ & $\begin{array}{l}\text { Todas las } \\
\text { democracias }\end{array}$ \\
\hline Parlamentario & 18 & 13 & 12 & 43 \\
\hline Presidencialista & 2 & 3 & 27 & 32 \\
\hline $\begin{array}{l}\text { Semi- } \\
\text { presidencial }\end{array}$ & 4 & 4 & 12 & 20 \\
\hline
\end{tabular}

Fuente: www.idehpucp.pucp.pe

OECD: Organización Económica para la Cooperación y el Desarrollo

BTI: Bertelsmann Transformation Index.

En cambio para ordenar los criterios de Morlino y Merkel en relación al caso de México se diseñó un cuadrante de correspondencia entre cada concepto y la evidencia en el desempeño democrático de México.

En el cuadro 5 las dimensiones marcadas con una $\mathrm{X}$ indican fallas institucionales del orden democrático, tanto en los criterios de Morlino como de Merkel. Véase como de las 6 dimensiones de una democracia imperfecta México no cumple con cinco de ellas, por lo tanto pude definirse como una democracia imperfecta. Y de acuerdo a las dimensiones de Merkel al situarse México con dos dimensiones no funcionales de cuatro en total pude definirse nuestra democracia como defectuosa. 


\section{Cuadro 5. Dimensiones del desempeño democrático en México.}

\begin{tabular}{|l|c|l|c|}
\hline $\begin{array}{l}\text { Democracia } \\
\text { defectuosa } \\
\text { (dimensiones) }\end{array}$ & México & $\begin{array}{l}\text { Democracia } \\
\text { imperfecta } \\
\text { (dimensiones) }\end{array}$ & México \\
\hline $\begin{array}{l}\text { Democracia } \\
\text { exclusiva }\end{array}$ & $\mathrm{Xstado}$ de derecho & $\mathrm{X}$ \\
\hline Democracia tutelada & $\mathrm{X}$ & $\begin{array}{l}\text { Responsabilidad } \\
\text { electoral }\end{array}$ & $\begin{array}{l}\text { Responsabilidad } \\
\text { interinstitucional }\end{array}$ \\
\hline $\begin{array}{l}\text { Democracia } \\
\text { delegativa }\end{array}$ & $\mathrm{X}$ & Reciprocidad & $\mathrm{X}$ \\
\hline Democracia iliberal & & Libertad & $\mathrm{X}$ \\
\hline & & Igualdad & $\mathrm{X}$ \\
\hline
\end{tabular}

Fuente: Elaboración del autor.

\section{Número dos.}

El sistema político mexicano esta edificado sobre una constitución que garantiza la división de poderes en el marco de un sistema presidencial, la dualidad ayer y hoy en el uso alternativo de las reglas formales e informales parece marcar un anómalo funcionamiento de la democracia mexicana.

Este disímbolo accionar institucional ha hecho sostener a algunos (priistas por ejemplo) que México siempre ha sido una nación democrática por tener una Constitución republicana, representativa, federalista desde 1917. En cambio para otros la democracia se materializo en el año 2000 con el arribo al cargo del Ejecutivo Federal por el partido Acción Nacional y el consecuente desalojo del PRI de los pinos. Otros (perredistas por ejemplo) sostienen que en México todavía no hay democracia.

Se repite hoy la confusión analítica del pasado del sistema político mexicano, -pero ahora- el debate no es sobre el tipo de régimen (democrático, autocrático, totalitario) sino sobre la calidad democrática, y en ello está presente la calidad institucional, confeccionada por 
actores políticos del pasado no democráticos. Cinco décadas atrás la imposibilidad de ubicar a México como democracia o dictadura derivo en un sinnúmero de interpretaciones.

En cambio hoy el debate es sobre la calidad democrática, o lo que yo llamo '“.'Desempeño Democrático $\cdots \cdot$ De tal forma que el desempeño de la democracia mexicana está relacionado en primer lugar por la herencia institucional, y en segundo lugar por el tipo de transición que abrió paso a la democratización del régimen.

La herencia institucional anómala del actual orden democrático defectuoso está relacionada con la pervivencia y primacía de las reglas informales como mecanismo orientador de la competencia política y la debilidad por lo tanto del Estado de derecho. De allí que coincidan tanto Morlino como Merkel en ubicar a México en esta dimensión (Rule of Law) en donde las leyes son subordinadas por los propios gobernantes.

Entonces el actual Desempeño Democrático de México (defectuoso) es producto de una desviación institucional que no ha conducido a una consolidación democrática, Esta desviación (debilidad del Estado de derecho) mantiene a México en un '..'Entrampe

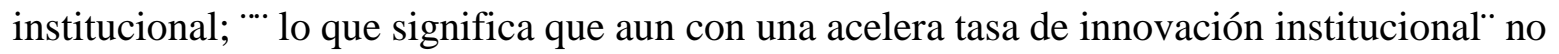
se logra la eficiencia institucional.

Y cuando hablamos de eficiencia institucional nos referimos a la necesaria relación positiva entre cambios institucionales de forma y función. Por ejemplo -esta paradoja- donde los actores políticos han consumido más de 25 año de reformas electorales modificando las normas e instituciones sin un impacto en la calidad democrática es ilustrativa.

La tendencia a la innovación institucional, o reformismo social como le llamo Arnaldo Córdova (1973) es una herencia del régimen autoritario que se repite hoy con otro escenario, pero bajo las mismas premisas legitimadoras para los gobernantes. 
Este accionar reformador hoy lo ejercen los partidos políticos perdedores en cada elección lo que significa altos costos de oportunidad y altos costos de transacción política en detrimento de políticas para el desarrollo económico, la equidad social y el bienestar de los mexicanos.

La herencia autoritaria impregno el accionar actual de los actores políticos de tal forma que este entrampe institucional tiene dos orígenes, el ya citado de la preminencia de las instituciones informales y el otro es la singular transición hacia la democracia que experimento México.

La peculiaridad de la transición política de México reside en que no surgió de la expulsión de un dictador, la derrota a un régimen comunista o una revolución social. No se vivió un repudio generalizado al partido gobernante (Partido Revolucionario Institucional) ni sucumbió electoralmente ni desapareció, no se dividió (al menos formalmente) y ni siquiera se debilito organizacionalmente.

Muy al contrario (paradoja institucional) el partido gobernante contribuyo al cambio institucional con todo y sus defectos y desviaciones que este mismo partido instrumentó por décadas para repartir y reciclar el botín político.

El PRI en otras palabras no perdió el poder de la noche a la mañana, ni se le desplazo de la escena política nacional, pues al ser parte del proceso democratizador, negocio una transición pactada y gradual centrada en reformas electorales en las que se cifro todo el anhelo democrático y con ello todos los sueños redentores que la democracia nos cumpliría situándonos en el edén del progreso económico y el bienestar social. El problema yace, precisamente en que la transición se limitó a lo electoral, dejando todo lo demás al azar. ${ }^{10}$

\footnotetext{
${ }^{10}$ Rubio Luis. De la falsa monarquía al feudalismo imperfecto: www.nexos.com.mx
} 
Por lo tanto, la combinación defectuosa de la preeminencia de instituciones informales, un ineficaz Estado de derecho y una transición centrada en lo electoral alientan hoy un cumulo de interpretaciones académicas y expectativas sociales que no satisfacen a unos u otros. Sobre todo se repite la misma confusión conceptual de nuestro sistema político de ayer, pero hoy es acerca del tipo, calidad y sobre las normas democráticas que aseguren estabilidad y gobernabilidad.

\section{Cuadro 6. Herencia y desempeño democrático de México.}

\begin{tabular}{|l|l|l|l|l|}
\hline Tipo de actores & $\begin{array}{l}\text { Tipo de } \\
\text { transición }\end{array}$ & $\begin{array}{l}\text { Eje del proceso } \\
\text { democratizador }\end{array}$ & $\begin{array}{l}\text { Herencia } \\
\text { institucional }\end{array}$ & $\begin{array}{l}\text { Desempeño } \\
\text { democrático }\end{array}$ \\
\hline $\begin{array}{l}\text { Pragmáticos- } \\
\text { negociadores }\end{array}$ & Pactada-gradual & $\begin{array}{l}\text { Normas e } \\
\text { instituciones } \\
\text { electorales }\end{array}$ & $\begin{array}{l}\text { Preeminencia de } \\
\text { instituciones } \\
\text { informales. } \\
\text { Ineficaz Estado } \\
\text { de derecho }\end{array}$ & $\begin{array}{l}\text { Paradoja entre } \\
\text { innovación } \\
\text { institucional y } \\
\text { eficiencia } \\
\text { institucional. }\end{array}$ \\
\hline
\end{tabular}

Fuente: elaboración del autor.

\section{Conclusiones}

La herencia institucional de la actual democracia mexicana fue la preeminencia de instituciones informales en todo tipo de competencia e intercambio político entre individuos maximizadores y egoístas. Sus parámetros para la acción y las elecciones se daban bajo una racionalidad limitada; así la ideología de la revolución mexicana fue un eficaz sustituto de información incompleta y asimétrica que el régimen autoritario encarecía al volver confuso, contradictorio o discrecional el uso alternativo de las reglas formales o informales.

La vocación reformista de la clase gobernante, más su herencia popular-revolucionaria le doto al régimen priista un accionar modernizador; así el cambio institucional ayudo también al régimen posrevolucionario a procesar los conflictos sociales y políticos bajo la premisa de bien común.

Hoy el desempeño democrático de México sea definido como anómalo, defectuoso o imperfecto da cuenta de una transición peculiar en donde el rival a derrotar fue estratégicamente abriendo el sistema al pluralismo sin devenir en un derrocamiento violento 
El desempeño democrático, concepto creado por el suscrito permite entender las cualidades y defectos de la democracia mexicana integrando el enfoque neo institucional para combinar una explicación del funcionamiento de la democracia desde la perspectiva de los individuos (individualismo metodológico) y de los actores políticos (enfoque sistémico u holista.

Nuestra aportación en este trabajo se centra en enfatizar que el desempeño democrático de México está relacionado con las reglas, los individuos y las organizaciones y que los tres componentes casi siempre se encuentran en un equilibrio inestable. De allí que todo cambio institucional (democratización) genera tensiones y conflictos distributivos. Hasta la fecha el sistema político mexicano ha sido exitoso en el procesamiento de estos conflictos, esta es otra herencia del régimen autoritario. 


\section{Referencias}

Córdova Arnaldo, La ideología de la Revolución Mexicana. México. Editorial Era. Decimoprimera edición.1983.

Fundación Konrad-Adenauer-Stiftung, Índice de Desarrollo Democrático de América Latina 2015. Uruguay. Ubicado en www.idd-lat.org

Linz Juan, Los peligros del presidencialismo. En El resurgimiento Global de la democracia, Diamond Larry y Marc F. Plattener (compiladores). Instituto de Investigaciones Sociales. UNAM. México.1996.

Merkel Wolfgang, ¿Democracias liberales o defectuosas? América Latina en el contexto internacional. Ubicado en http://www.idehpucp.pucp.pe

Meyer Lorenzo, El limite neoliberal. Revista Nexos. No. 163. México. 1991.

Molinar Horcasitas Juan, Escuelas de interpretación del sistema político mexicano. Revista Mexicana de Sociología, año LV. Año LV. Núm. 2, abril -junio de 1993.

Morlino Leonardo, "'.Explicar la calidad democrática:¿Qué tan relevantes son las tradiciones autoritarias..”. Revista de Ciencia Política. Volumen 27. No.2. Pontificia Universidad Católica de Chile. Ubicado en http://www.redalyc.org

Morlino Leonardo, La calidad de las democracias en América Latina. Instituto Internacional para la Democracia y la Asistencia Electoral. Costa Rica. 2014

Puhle Hans-Jurgen, Problemas de consolidación democrática y democracias defectuosas. Ubicado en http://www.top.org.ar 